\title{
Exercise Physiology and Stress
}

National Cancer Institute

\section{Source}

National Cancer Institute. Exercise Physiology and Stress. NCI Thesaurus. Code C18777.

The field of research concerned with the interaction between exercise physiology and stress. 